
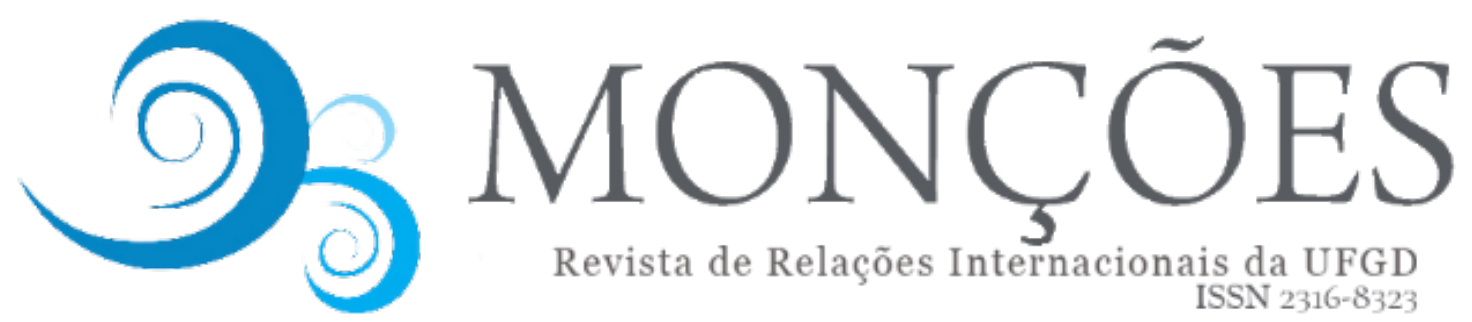

Revista de Relações Internacionais da UFGD

ISSN $2316-8323$

\title{
A AMBIVALÊNCIA DA POLÍTICA EXTERNA CHINESA E O PROGRAMA NUCLEAR DA COREIA DO NORTE
}

\section{Bruna Miranda Dias \\ Graduada em Relações Internacionais pela Universidade Vila Velha (UVV).}

\begin{abstract}
Helvécio de Jesus Júnior
Doutor em História pela Universidade Federal do Espírito Santo (UFES); Mestre em Relações Internacionais pela Pontifícia Universidade Católica do Rio de Janeiro (PUC-RIO) e Professor titular do curso de Relações Internacionais da Universidade Vila Velha (UVV).
\end{abstract}

RESUMO: O presente estudo busca analisar a relação China-Coreia do Norte e como a questão nuclear contribuiu para moldar a forma com que a política externa chinesa é implementada na região ao longo dos anos. Essa relação, que teve seu início marcado com a Guerra da Coreia, pode ser vista através de uma série de pensamentos convencionais e que ao longo do tempo serviram para explicar a maneira ambivalente como a China se portou para com a Coreia do Norte. Não obstante, após mais de uma década de testes com Armas de Destruição em Massa norte-coreanos, o modo pelo qual os assuntos de segurança internacional se desenvolveram fez com que esses pensamentos se tornassem insuficientes para explicar o comportamento de uma China, que agora ocupa uma posição de grande potência mundial, e possui maior responsabilidade para com a comunidade internacional, dada a ameaça que a República Democrática Popular da Coreia (RDPC) passou a representar.

PALAVRAS-CHAVE: China; Coreia do Norte; Questão Nuclear.

\section{THE AMBIVALENT CHINESE FOREIGN POLICY AND THE NORTH KOREA'S NUCLEAR PROGRAM}

ABSTRACT: The present essay aims to analyze the China-North Korea relationship and also how the nuclear issue has contributed to shape the way chinese foreign policy is implemented in the region throughout the years. This relationship, which had its beginning marked by the Korean War, can be seen through a series of conventional thoughts that for a long time served as an explanation to the ambivalent way China has been behaving towards North Korea. Nevertheless, after more than one decade of North-Korean Weapons of Mass Destruction (WMD) tests, the way how the international security issues have developed made these thoughts no longer sufficient to explain the behavior of a China that now occupies a place of a great global power, and has also a lot more responsibility to the international community given the threat Democratic People's Republic of Korea (DPRK) has become.

KEYWORDS: China; North Korea; Nuclear issue. 
Durante mais de meio século China e Coreia do Norte mantêm uma relação marcada por uma série de acontecimentos importantes na história mundial. Se o início dessa cooperação se deu em 1950, com a Guerra da Coreia, onde ao ver seu território ameaçado por uma invasão de tropas estadunidenses, a China enviou auxílio ao exército norte-coreano, hoje essa relação pode ser analisada por um outro ponto de vista.

Desta maneira, o artigo visa analisar através de fatos históricos e empíricos, a relação entre China e Coreia do Norte, de forma a pontuar como a política externa chinesa tem se mostrado ambivalente ao longo dos anos. Seja em sua atuação no Conselho de Segurança da ONU, nas Six Party Talks, ou nas diversas formas de comércio utilizadas entre Beijing e Pyongyang, há sempre na forma como a China trata a questão nuclear norte-coreana, uma dualidade questionada pela comunidade internacional em seu comportamento. Portanto, com a finalidade de abranger pontos importantes para o entendimento das ações de política externa chinesa para com a Coreia do Norte no que diz respeito à questão nuclear, bem como das possíveis consequências e cenários para os quais essas contribuem, foram designadas 4 seções específicas ao longo do artigo.

A primeira seção, intitulada: $A$ relação China-Coreia do Norte: entendendo o contexto histórico, foi desenvolvida com o intuito de configurar uma perspectiva geral de como a cooperação entre os dois países se deu desde seu início em 1950 até dias mais atuais, de forma a situar os acontecimentos históricos que marcaram essa relação desde seu começo.

Já a segunda seção, nomeada: As peculiaridades da política externa chinesa para a Coreia do Norte, tem o intuito de mostrar como se dá a ambivalência da política externa chinesa em relação a Coreia do Norte, principalmente no que diz respeito ao posicionamento chinês sobre a questão nuclear, que tem se agravado no decorrer dos anos. Esta seção se aprofunda também no conceito de pequeno poder, explicando a razão pela qual a Coreia do Norte pode ser caracterizada como tal e o que isso significa, não só em seu modo de agir com a China, mas com todos os outros países de seu interesse. 
A terceira seção, com o título: Os benefícios e os prejuízos da relação dual e contraditória, trata da cooperação entre os dois países e as vantagens e desvantagens que ela traz para cada um deles, seja no campo político-estratégico ou na área econômica. Essa seção se propõe a demonstrar, mais uma vez, através de análise de dados, o quão ambivalente tem sido a política externa chinesa em face dos prós e contras de sua relação com a Coreia do Norte. Por fim, em decorrência da ameaça que a República Democrática Popular da Coreia (RDPC) passou a representar perante a comunidade internacional, e devido a novos fatores de mudança no cenário internacional, como a recente transição do governo estadunidense em 2017, de Obama para Trump, a última seção busca analisar três possíveis cenários para a resolução do impasse nuclear, como resultado do aumento das tensões na península coreana.

\section{A relação China-Coreia do Norte: entendendo o contexto histórico}

Ao analisarmos a relação entre China e Coreia do Norte temos de levar em conta o fato histórico que marca o início do que mais tarde se tornaria uma política ambivalente por parte da China: a Guerra da Coreia (1950-1953). Quando ao ver Pyongyang, capital da Coreia do Norte, tomada pelas tropas do general MacArthur, que se aproximava do Rio Yalu, na fronteira sino-coreana, a China iniciou seus preparativos militares de modo a deixar claro que não toleraria uma Coreia do Norte devastada. Assim, a China entrou no conflito em novembro de 1950 fazendo com que as tropas da ONU recuassem (VIZENTINI e PEREIRA, 2014). O conflito terminou com a assinatura de um armistício, e deixou as duas Coreias arrasadas e separadas pelo paralelo 38, onde se encontra a Zona Desmilitarizada.

Com o Sul recebendo o apoio dos Estados Unidos, o Norte ficou dependente da União Soviética e da China, de modo que Beijing e Pyongyang passavam a estar conectados também pela ideologia comunista. Não apenas sua ideologia contribuiu para que os laços entre os dois países pudessem ser aprofundados, mas principalmente pelo fato de que a Coreia do Norte passava então a representar um Estado-tampão para a China, de maneira que manteria as tropas estadunidenses 
estacionadas na vizinha Coreia do Sul, longe de uma parte sensível do território chinês (VIZENTINI e PEREIRA, 2014).

Em 1961 esta aliança estratégica seria ratificada com a assinatura do Tratado de Amizade, Cooperação e Assistência Mútua entre a República Popular da China (RPC) e a Coreia do Norte. Tratado esse que previa, no caso de uma das partes ser atingida por um ou mais Estados, e se encontrasse em estado de guerra, envio de total auxílio militar da outra parte ${ }^{1}$.

Não obstante, a década seguinte trouxe consigo uma mudança nas relações político-diplomáticas entre Beijing e Washington. Ao se estabelecer a chamada "Diplomacia do Ping-Pong", a China começava a sua reaproximação com os Estados Unidos, além de passar a ocupar oficialmente um assento permanente no Conselho de Segurança da ONU, antes ocupado por um representante de Taiwan, em uma demonstração contrária à URSS. Tal reaproximação fez com que Pyongyang visse sua relação com Beijing se deteriorar (VIZENTINI e PEREIRA, 2014). Essa mudança na política externa chinesa configurava o rascunho de como seria o tratamento para com a Coreia do Norte, uma vez que a China agora começava a trilhar o caminho que a firmaria como um Global Player, principalmente na área econômica, e não somente como um líder regional. Enquanto isso, a Coreia do Norte entendia a atitude chinesa como uma traição, o que forçou Pyongyang a buscar uma aproximação com Seoul. Essa atitude provocou a seguinte reação do governo chinês, conforme afirma Lee (1996, p. 67-68):

Os chineses acolhiam o diálogo entre Pyongyang e Seoul (...). Ainda que reiterando seu comprometimento para com a defesa norte-coreana e expressando preocupação acerca da modernização militar sulcoreana, os chineses esperavam que o Comunicado Intercoreano serviria como quadro para a institucionalização da cooperação pacífica e da estabilidade militar na Península Coreana. Eles estavam receosos de que uma escalada das tensões na Coréia poderia perturbar o frágil novo relacionamento chinês com os EUA e com o Japão, ou que a URSS poderia tirar vantagem da situação instável para avançar com

\footnotetext{
${ }^{1}$ Um ataque iniciado pela Coreia do Norte à vizinha Coreia do Sul, ao Japão e/ou aos Estados Unidos, no entanto, não abrange os termos deste tratado. Se isso de fato acontecesse, Beijing estaria desobrigada de enviar auxílio a Pyongyang. Caso o cenário seja inverso, e qualquer outro país faça o primeiro ataque à Coreia do Norte, a China sim teria de enviar apoio à RDPC. Porém, segundo Shen Dingli (2006), Beijing demonstra cada vez menos interesse em cumprir o Artigo II do Tratado de Amizade, Cooperação e Assistência Mútua, feito com Pyongyang.
} 
seus interesses estratégicos de longa-data na Coréia. (apud. MELCHIONNA, 2011, p.24).

Mas Pyongyang nunca deixou de representar uma importante chave na estratégia geopolítica de Beijing, e Kim II-Sung, o primeiro-ministro e depois presidente norte-coreano de 1949 a 1994, entendia isso de forma que procurava se beneficiar da rivalidade entre China e União Soviética (URSS), como expõe Lee (1996, p. 70):

No início dos anos 1980, os chineses competiam vigorosamente com a URSS para cortejar Pyongyang por meio de garantias de segurança, patrocínio diplomático, e assistência econômica (...). Os chineses não podiam se dar ao luxo de perder a Coreia do Norte como aliada militar ou de vê-la apoiar a estratégia soviética na região do Pacifico: se a Coreia do Norte permitisse que a URSS aquartelasse divisões na península ou utilizasse Najin ou Nampo como bases navais, a segurança da China estaria ameaçada. Como havia sido durante a Guerra da Coreia, os chineses acreditavam que qualquer força militar estrangeira na Coreia do Norte ameaçaria seus interesses na região Nordeste e no Mar Amarelo. Dado a deterioração das relações da China com outros países socialistas, tais como Vietnã , Cuba, Mongólia e Albânia, a importância relativa da Coreia do Norte ampliou-se. (apud. MELCHIONNA, 2011, p. 27).

Após a ascensão ao poder na China de Deng Xiaoping e a consequente mudança na orientação da política externa chinesa, agora voltada para a promoção da estabilidade econômica do país assim como a paz regional, a China passou a buscar parceiros econômicos vizinhos como o Japão e a Coreia do Sul. Além disso, Beijing buscou também reestabelecer os laços com a URSS o que limitou o poder de barganha da Coreia do Norte que passou a buscar outros aliados em países do Terceiro Mundo (MELCHIONNA, 2011).

Já na década de 1990, após o colapso da União Soviética e, consequentemente, o fim da Guerra Fria, a Coreia do Norte sofreu com os impactos da perda de um dos seus maiores parceiros e ainda mais com as enchentes de 1995 e 1996 e a seca de 1997 que configuraram o período marcado como a Grande Fome, o que resultou na morte de aproximadamente 2 milhões de norte-coreanos. Além disso, em 1994 com o falecimento de Kim II-Sung e decorrente instabilidade política, sobe ao poder Kim Jong-II. É também durante a década de 1990 que a China estreita suas relações com a Coreia do Sul de modo a não vetar mais sua 
entrada na Organização das Nações Unidas (ONU), adotando assim, não mais a política de "uma Coreia", mas sim a que assume atualmente, "duas Coreias" (MELCHIONNA, 2011).

A aproximação chinesa da Coreia do Sul sinalizava, portanto, uma mudança em sua política externa para o leste asiático. Conforme explica Melchionna (2011), Beijing passa, a partir dos anos 1990, a implementar uma nova política para a região que visava substituir a antiga tensão que a bipolaridade das décadas passadas imprimiu na península. Desta forma, a China começa a dar maior prioridade em sua política aos países vizinhos do leste asiático, especialmente às duas Coreias.

Por outro lado, enquanto Beijing se esforçava por se aproximar de Seoul, a Coreia do Norte, via na presença dos Estados Unidos com suas ogivas nucleares à postos na vizinha Coreia do Sul durante o período da Guerra Fria, uma razão mais do que suficiente para perseguir a capacidade nuclear, o que já na década de 1990 e no início do século que estava por vir, daria a Pyongyang novamente poder de barganha, desta vez, porém entre China e Estados Unidos.

Segundo Sivels (2013), a data estimada do início do programa nuclear nortecoreano é a década de 1950. Muitos de seus cientistas de primeira geração foram educados em universidades do Japão na década de 1930 e haviam retornado em 1940. Já a segunda geração teria se beneficiado tanto da expertise dos cientistas de primeira geração, quanto do aprimoramento do conhecimento fornecido pelo treinamento avançado na União Soviética, a qual em 1956 assinaria acordos de uso pacífico de energia atômica e colaboração em estudos de ciência nuclear. Com a ajuda da URSS, em 1962, seria implantado em Yongbyon na Coreia do Norte, o Centro de Pesquisas em Energia Atômica, bem como seriam fornecidos diversos equipamentos necessários à pesquisa e desenvolvimento nuclear.

Em abril de 1985 a RDPC passou a integrar o quadro de países membros do Acordo de Não Proliferação Nuclear, além de ter ingressado na Agência de Energia Atômica Internacional (AEAI), por pressão da União Soviética, e assinou acordos que permitiriam a AEAl inspecionar os sítios do programa nuclear norte-coreano (SIVELS, 2013). Contudo, quando a AEAI solicitou uma inspeção especial em Yongbyon sob suspeitas de maior reprocessamento de plutônio, a Coreia do Norte não somente impediu a inspeção, como também ameaçou se retirar do Tratado de Não Proliferação de Armas Nucleares (TNP) (MELCHIONNA, 2011). 
Mediante a instabilidade da situação, conforme citado por Lee (apud MELCHIONNA, 2011, p.43), a China se viu diante de um grande dilema, de forma que:

A China favorecia uma Coréia desnuclearizada e uma resolução negociada da questão nuclear norte-coreana, mas se opunha a quaisquer sanções econômicas patrocinadas pela ONU contra a Coréia do Norte ou a um ataque aéreo contra as instalações nucleares nortecoreanas porque ela percebia que qualquer uma destas ações poderia desencadear uma séria confrontação militar na península coreana.

Posteriormente, com o colapso do Acordo Quadro, assinado entre Pyongyang e Washington, e que demandava da Coreia do Norte a permanência no TNP, e com a interrupção das inspeções feitas pela AIEA em seu território, assim como a paralisação do envio de petróleo pesado por parte da Organização para o Desenvolvimento Energético da Península Coreana $(K E D O)^{2}$ à RDPC, em 2003 a Coreia do Norte se retira do Tratado de Não Proliferação, o que resulta em uma outra iniciativa, as Six Party Talks (SIVELS, 2013).

As Six Party Talks (SPT) tinham o objetivo de amenizar a crise e tentar convencer Pyongyang a abrir mão de seu programa nuclear através do diálogo. Integravam as rodadas das conversações a Coreia do Norte, a China, os Estados Unidos, a Coreia do Sul, o Japão e a Rússia. No entanto, ao apresentarem sua proposta, os Estados Unidos sofreram rejeição dos termos por parte de Pyongyang. Já China e Rússia demonstravam certo apoio a alguns termos da proposta reward for freeze ${ }^{3}$, apresentada pela Coreia do Norte, e passaram a demonstrar discordância em relação ao discurso adotado por Bush (MELCHIONNA, 2011). Assim, em fevereiro de 2005 a Coreia do Norte interrompeu as Six Party Talks, alegando a não produtividade das conversações e somente em julho de 2005, sob pressão chinesa, Pyongyang voltaria a integrar as rodadas, mas por um curto período de tempo. Desta vez, devido ao corte dos fundos norte-coreanos por parte

\footnotetext{
${ }^{2} \mathrm{~A}$ KEDO, sigla que significa no inglês Korean Peninsula Energy Development Organization, foi criada inicialmente pelos Estados Unidos, Japão e Coreia do Sul, e tinha o intuito de fornecer auxílio à Coreia do Norte na construção de dois reatores de água-leve e 500 mil toneladas de petróleo pesado, segundo os termos de compromisso do Acordo Quadro.

${ }^{3}$ Reward for freeze representa o termo usado para se referir à proposta inicial norte-coreana nas Six Party Talks, e que segundo Melchionna (2011) "incluía uma garantia formal de não agressão dos EUA; um congelamento de longo-prazo de seu programa nuclear de reprocessamento de plutônio; e a retenção pelo país de um programa nuclear com fins pacíficos".
} 
dos Estados Unidos, em novembro de 2005, a Coreia do Norte interromperia novamente as Six Party Talks, o que resultou no primeiro teste nuclear nortecoreano em outubro de 2006 (SIVELS, 2013).

De acordo com Feng (2006), a atitude da China começou a mudar após os constantes relatos de iminentes testes de mísseis de longo alcance por parte da Coreia do Norte, em junho de 2006, o que fez com que, pela primeira vez, Beijing demandasse de Pyongyang o encerramento de suas atividades nesse campo. Porém, como uma demonstração de desprezo ao esforço chinês de trazer estabilidade à península coreana, Pyongyang prosseguiu com os testes, até seu primeiro teste nuclear em outubro de 2006. Assim, em uma mudança significativa com relação à política adotada anteriormente para a Coreia do Norte, que não concordava com a imposição de sanções, pensando ser uma forma de evitar o aumento das tensões, a China adotou a Resolução 1695 do Conselho de Segurança que condenava os testes com mísseis realizados e impunha sanções limitadas (FENG, 2006).

Após o primeiro teste nuclear norte-coreano, Beijing se viu forçada a adotar uma nova Resolução do Conselho de Segurança, a Resolução 1718, que impunha novas sanções à Coreia do Norte, fato que reafirmava a mudança no comportamento chinês. Contudo, mesmo essa Resolução só foi adotada depois de revisada, e da retirada de imposições mais duras contra a Pyongyang (FENG, 2006).

Não obstante, a retomada das Six Party Talks que parecia estar ainda mais distante em vista dos acontecimentos, voltou a ocorrer em dezembro de 2006. Demonstrando, ao contrário das expectativas, certa melhora em 2007, quando foi assinado um novo acordo entre os países membros e que concedia por parte dos Estados Unidos, alguns dos requerimentos feitos pela Coreia do Norte. Por sua vez, a RDPC se comprometia a desativar seu sítio nuclear em Yongbyon e permitir novamente a entrada da AEAl para inspeção. No entanto, novas divergências surgiram entre Pyongyang e Washington fazendo com que as rodadas não obtivessem nenhum progresso e, dessa forma, as conversações foram novamente interrompidas em 2008 (MELCHIONNA, 2011).

Um novo teste nuclear norte-coreano aconteceria em maio de 2009 , o que segundo Glasser (2009), teria deixado Beijing furiosa com a RDPC. O segundo teste nuclear norte-coreano levou a China a adotar sanções mais duras do que o previsto 
na Resolução 1718 e que dizia respeito ao primeiro teste nuclear norte-coreano. Mas apesar de desejar uma península coreana desnuclearizada, a China sabia do risco que corria caso pressionasse em demasia a Coreia do Norte (GLASSER, 2009).

A adoção da Resolução 1874 do Conselho de Segurança seguiu-se de um pronunciamento do porta-voz do Ministro das Relações Exteriores da China, que segundo Glasser (2009), reafirmava a oposição chinesa ao teste, mas enfatizava que as sanções adotadas pela China não tinham a intenção de punir a RDPC, e sim de persuadi-la a reconsiderar as suas ações e retomar as negociações. A resposta oficial do governo chinês ao teste seguia essa mesma lógica. Demandava o comprometimento norte-coreano com a desnuclearização e sua volta as Six Party Talks, dessa forma demonstrando mais uma vez sua oposição ao teste.

Contudo, a Coreia do Norte ainda realizaria mais testes nucleares, sendo o terceiro deles conduzido em fevereiro de 2013 e com o rendimento previsto pelo Ministério da Defesa da Coreia do Sul entre 6 e 7 kilotons, o que caracteriza um aumento significativo se comparado aos testes anteriores que alcançaram $1 \mathrm{Kt}$ (2006) e 4 Kts (2009). Esse novo teste também contribuía para a percepção da potencial melhora da capacidade norte-coreana em produzir ogivas nucleares suficientemente pequenas para que coubessem em um míssil intercontinental balístico (SIVELS, 2013). O novo teste nuclear norte-coreano provocou na China uma reação parecida com as anteriores. Beijing adotou então a Resolução 2094 do Conselho de Segurança que autorizava a imposição de novas sanções a Pyongyang (WANG, 2014).

Em 2016, a Coreia do Norte faria mais dois novos testes nucleares, um em janeiro e outro, o quinto até então, em setembro deste mesmo ano. Ambos foram seguidos pela adoção unânime do Conselho de Segurança das Resoluções 2270 e 2321, respectivamente, e que condenavam as atividades nucleares de Pyongyang de maneira veemente, reafirmando a violação das Resoluções anteriores, bem como a violação do TNP.

Em resposta ao primeiro teste de 2016, a porta-voz do governo chinês, HuaChunying, disse que:

A China está firme em sua posição de que a Península Coreana deveria ser desnuclearizada e a proliferação nuclear deveria ser 
evitada para que sejam mantidas a paz e a estabilidade no Nordeste Asiático. Incitamos fortemente a RDPC a honrar seu compromisso com a desnuclearização, e a cessar qualquer ação que venha a deteriorar a situação.(CHUNYING, 2016, tradução nossa). ${ }^{4}$

$\mathrm{Na}$ ONU, o representante chinês disse que a Resolução 2270 serviria como um ponto de partida para aliviar as tensões na península coreana, dando ênfase à retomada das negociações de paz e ao avanço da desnuclearização da região.

Em março de 2017, segundo dados divulgados no site do Ministério das Relações Exteriores chinês, representantes do Governo da China e dos Estados Unidos se reuniram com o propósito de discutir a situação da península coreana. Ambos os lados teriam então demonstrado a vontade de contribuir para a diminuição das tensões e a promoção da desnuclearização e estabilidade da região.

Todo o esforço diplomático chinês, contudo, não impediu que em julho de 2017 a RDPC realizasse novos lançamentos de mísseis balísticos de longo alcance, aumentando as tensões entre os Estados Unidos na Península Coreana, e assim resultando no sexto teste nuclear norte-coreano em 3 de setembro deste mesmo ano.

\section{As peculiaridades da política externa chinesa para a Coreia do Norte}

Ao longo das décadas o crescimento chinês e o lugar que a China passou a ocupar no cenário internacional moldou a sua política externa para seus vizinhos asiáticos, especialmente a Coreia do Norte. A política de "diplomacia periférica”, ou 周边外交, zhoubianwaijiao, adotada pela China a partir dos anos 1990 para se relacionar com os países asiáticos, enfatiza a postura de um comportamento que vem a ser caracterizado por um viés muito mais diplomático que de confronto, uma vez que Beijing passa então a assumir um posicionamento alinhado ao de uma potência em ascensão, e que almeja solidificar seu lugar no cenário internacional

\footnotetext{
${ }^{4}$ China is steadfast in its position that the Korean Peninsula should be denuclearized and nuclear proliferation should be prevented to maintain peace and stability in Northeast Asia. We strongly urge DPRK to honor its commitment to denuclearization, and to cease any action that may deteriorate the situation.
} 
BRUNA M. DIAS \& HELVÉCIO DE JESUS JR.

(MENEGAZZI, 2017). Não obstante, a China ainda mantém uma política ambivalente perante a comunidade internacional, que ao observar o comportamento chinês em relação a península coreana, o faz com desconfiança.

Essa mudança no posicionamento chinês, que incluiu a retomada das relações com países como a Coreia do Sul, Japão e Estados Unidos, aliada ao comportamento dual com relação a questão nuclear norte-coreana, fez com que o que anteriormente, durante o período da Guerra Fria, era tido como afinidade e motivo de aproximação entre Pyongyang e Beijing, não mais fosse suficiente para manter essa conexão. A partir do momento em que a Coreia do Norte passou a realizar testes nucleares e com mísseis balísticos de longo alcance, demonstrando cada vez menos compromisso em cooperar na estabilização do cenário internacional, as relações entre China e RDPC sofreram certo esfriamento, porém não deixaram de existir (WANG, 2014).

Em discurso realizado em 2013, após o terceiro teste nuclear norte-coreano, o Ministro das Relações Exteriores Chinês, Yang Jiechi, ao se pronunciar sobre a adoção da Resolução 2094, reforçou que essa medida não deveria caracterizar uma mudança fundamental na direção da política entre China e Coreia do Norte (WANG, 2014).

$\mathrm{Na}$ visão de Wang (2014) o modo como a China implementa sua política externa com relação a Pyongyang pode ser explicado através de três motivos principais. O primeiro deles diz respeito ao comportamento da Coreia do Norte que, ao agir segundo os seus próprios interesses perante a comunidade internacional, faz disso uma vantagem para uso de barganha com a China. O que leva ao segundo motivo que assume que Beijing tem muito mais a perder em um conflito na região e por isso fica, de certo modo, refém das ações de Pyongyang. O terceiro e último ponto na visão de Wang, fala sobre a crescente presença militar dos Estados Unidos na região e principalmente na vizinha Coreia do Sul, fato que contribui para o aumento da desconfiança de Beijing em relação a Washington.

Para explicar a ambivalência da relação China-Coreia do Norte, Wang (2014) utiliza a teoria de "Pequeno Estado, Grande Influência" baseada no artigo de Robert Keohane "The Big Influence of SmallAllies", onde o autor analisa a influência de pequenos Estados sobre grandes potências, usando como exemplo a relação dos Estados Unidos com países como Israel e Taiwan. Dessa forma, um pequeno poder 
BRUNA M. DIAS \& HELVÉCIO DE JESUS JR.

é um Estado que, como a RDPC, tem seu interesse individual como primordial, e independente das consequências em maior escala, está disposto a adotar medidas drásticas, no caso de Pyongyang, iniciar uma guerra nuclear, uma vez que os resultados de uma ação assim não seriam tidos pelo pequeno poder como um prejuízo tão grande quanto para uma grande potência, como a China que tem muito mais a perder que a Coreia do Norte.

Segundo Rothstein (apud WANG, 2014, p.17, tradução nossa):

Um Pequeno Poder é um estado que tem o conhecimento de que não pode obter segurança primariamente apenas com o uso de suas capacidades, e que deve depender fundamentalmente da ajuda de outros estados, instituições, processos, ou desenvolvimentos para tanto; a crença do Pequeno Poder em sua inabilidade de dependência em seus próprios recursos deve também ser reconhecida pelos outros estados envolvidos na política internacional. ${ }^{5}$

Dessa forma, de acordo com o conceito de pequeno poder, a Coreia do Norte seria um Estado que entende sua dependência de outros Estados, principalmente da China, mas que a usa em seu próprio favor. No entanto, apesar de ser um pequeno poder, estritamente fechado e com um regime comunista rígido, Pyongyang conseguiu organizar um exército nacional, e aprimorar sua capacidade nuclear, ainda que essa não possa ser mensurada com exatidão, sendo percebida através da evolução dos testes realizados desde 2006. Deste modo, segundo Wang (2014), a RDPC constitui um pequeno poder instável e, que por não se julgar responsável, muito menos preocupado com as consequências para a comunidade internacional, pode estar disposto a levar suas provocações até o colapso com um conflito nuclear, uma vez que enxerga seu poderio nuclear como a melhor forma de sobrevivência para seu regime.

Já para a China que possui vantagens sobre a Coreia do Norte, utilizá-las se torna cada vez mais uma tarefa difícil. Com o arrefecimento das tensões na península no ano de 2017, a perda com um conflito na região representaria para Beijing um peso muito maior para a si do que para Pyongyang, justamente pelo fato de a China obter uma posição no cenário global de grande responsabilidade perante

\footnotetext{
${ }^{5}$ A Small Power is a state which recognizes that it cannot obtain security primarily by use of its own capabilities, and that it must rely fundamentally on the aid of other states, institutions, processes, or developments to do so; the Small Power's belief in its inability to rely on its own means must also be recognized by the other states involved in international politics.
} 
a comunidade internacional, de maneira que busca consolidar-se como uma grande potência mundial e global player.

A China desde do início das Six Party Talks, e também desde o primeiro teste nuclear norte-coreano em 9 de outubro de 2006, busca a estabilidade e a desnuclearização da península, e enxerga no comportamento instável da Coreia do Norte um fator de impedimento à implementação integral de sua política na região e por isso mantém sua posição, vista como dual para com Pyongyang, de forma a tentar alcançar uma península unificada e completamente pacificada através do diálogo diplomático e da adoção de sanções abrandadas (KONG, 2017).

Outro fator que contribui para a descrição da política chinesa como ambivalente, é a forma com que governo chinês age com relação aos chamados desertores norte-coreanos, que em sua maioria usam o território chinês apenas como parte de sua rota de fuga em busca do refúgio na vizinha Coreia do Sul. Por ainda ser a política chinesa dual, os chamados desertores recebem o status de imigrantes econômicos ilegais, o que faz com que, quando pegos, sejam entregues ao governo norte-coreano e punidos severamente, fato caracteriza a violação de um princípio dos direitos humanos, o non-refoulement, descrito no artigo 33 da Convenção de 1951, e da qual a China é signatária. ${ }^{6}$

Um exemplo do condicionamento da decisão de dar continuidade a essa política dual por parte da China pode ser visto também na década de 1990, quando a Beijing oficialmente estabeleceu laços diplomáticos com Seoul e reduziu sua ajuda econômica à Pyongyang. Como resultado dessa mudança em seu modus operandi, ao ver a Coreia do Norte à beira de um colapso com a Grande Fome, a China se viu obrigada a retomar sua ajuda econômica e alimentícia (KONG, 2017).

Já em 2005, quando a China se juntou aos Estados Unidos congelando as contas norte-coreanas em Macau sob a alegação de lavagem de dinheiro por parte da Coreia do Norte, a resposta de Pyongyang veio com a paralisação das SPT em

\footnotetext{
${ }^{6}$ Segundo o artigo 33 da Convenção de 1951: "Nenhum dos Estados Contratantes expulsará ou rechaçará, de maneira alguma, um refugiado para as fronteiras dos territórios em que sua vida ou a sua liberdade seja ameaçada em virtude da sua raça, da sua religião, da sua nacionalidade, do grupo social a que pertence ou das suas opiniões políticas". Mesmo que alguns dos desertores nortecoreanos possam caracterizados como imigrantes econômicos, estes se tornam refugiados surplace, que são aqueles refugiados que podem alegar o bem fundado temor de perseguição após a entrada em outro país, por medo de serem extraditados de volta ao seu país de origem e lá sofrerem maiores punições. Ciente disso, e sendo membro signatário tanto da convenção de 1951, quanto do Protocolo de 1967, a China, devido a condução de sua política externa para com a RDPC, continua a violar esses princípios.
} 
BRUNA M. DIAS \& HELVÉCIO DE JESUS JR.

novembro do mesmo ano e, posteriormente, em 2006 com a realização do primeiro teste nuclear norte-coreano (KONG, 2017) ${ }^{7}$.

Assim, acontecimentos como estes na história da relação China-Coreia do Norte serviram para configurar a postura chinesa, onde Beijing, por sua vez, passou a entender que seus objetivos na península coreana não poderiam ser alcançados através de medidas duras para com Pyongyang. A China entende, portanto, que é melhor buscar uma resolução de modo mais brando e diplomático, o que pode parecer à comunidade internacional como uma postura ambivalente, ao invés de assumir uma postura rígida e enfrentar o colapso do regime norte-coreano com o peso de uma transição incerta na península (KONG, 2017).

Desta maneira, a China, como uma grande potência no cenário internacional possui interesses que envolvem assuntos mais complexos do que para um pequeno poder como a Coreia do Norte. Ao mesmo tempo em que grandes potências como a China possuem maior capacidade econômico e militar, se comparadas aos pequenos poderes, não significa que poderão utilizar de seu poder como vantagem efetiva sobre países como a Coreia do Norte (WANG, 2014).

\section{Os benefícios e os prejuízos da relação dual e contraditória}

Se por um lado Wang (2015), especialista em assuntos de política e segurança asiáticos, defende uma visão que assume as premissas convencionais para a forma como a China se comporta em relação a Coreia do Norte, como insuficientes, Shen (2006), professor do Instituto de Estudos Internacionais da Universidade de Fudan em Shanghai, vê a cooperação entre os dois países como mútua dada a utilidade do território norte-coreano como Estado Tampão à China. $\mathrm{O}$ raciocínio de Shen, em seu artigo North Korea's Strategic Significance to China (2006), aponta que apesar de contribuir anualmente com uma soma de alguns bilhões, a China seria o lado mais beneficiado nessa relação, uma vez que a Coreia

\footnotetext{
${ }^{7}$ No site do Departamento do Tesouro dos Estados Unidos consta uma nota oficial acusando o Banco Delta Asia, localizado em Macau, de colaborar com o governo norte-coreano para fins de atividade financeira ilícita, e listando uma série de fatores pelo quais, mas não se limitando a eles, as instituições financeiras estadunidenses passariam a estar proibidas de manter qualquer tipo de movimentação de conta para ou em favor do Banco Delta Asia, o que resultou no congelamento de $\$ 25$ milhões de fundos norte-coreanos. $O$ texto completo poder ser encontrado em: https://www.treasury.gov/press-center/press-releases/Pages/js2720.aspx.
} 
do Norte, para Shen, estaria executando um papel fundamental para a segurança do território chinês, servindo de obstáculo entre a China e as tropas estadunidenses estacionadas na vizinha Coreia do Sul.

Dessa maneira, Beijing proporciona segurança para a RDPC, enquanto a Coreia do Norte representa em certa medida, um elemento importante para a segurança chinesa em uma parte de seu território que se mostra mais vulnerável. Por entender isso, a China se mostra pouco disposta a arriscar esse vínculo pressionando a Coreia do Norte, o que deixa os Estados Unidos com a tarefa de implementar medidas mais duras à RDPC (SHEN, 2006).

Outro ponto abordado por Shen (2006) é o interesse chinês em evitar a mudança de regime na Coreia do Norte que compartilha suas semelhanças com a China, e serve como um meio o qual Beijing utiliza para assegurar o comunismo ainda presente em seu próprio regime.

Para Wang (2014), a relação China-Coreia do Norte é altamente assimétrica e por isso resulta em benefícios tão diferentes para as partes. Enquanto Pyongyang é beneficiada em maior parte no aspecto econômico dessa troca, para Beijing esses benefícios se encontram muito mais na esfera político-estratégica de seus interesses como grande potência mundial, não podendo, portanto, levar em consideração apenas seus interesses nacionais, mas, principalmente as consequências que suas ações podem ter para a comunidade internacional, se tornando então, em certo nível, refém da Coreia do Norte.

Contudo, mesmo Shen, alguns anos depois em artigo à Foreign Policy, intitulado "Lips and Teeth: It's time for China to get tough on North Korea" (2013), admitiria uma mudança significativa na importância da RDPC como Estado Tampão para a China. Até mesmo o temor chinês de um fluxo incontrolável de migrantes norte-coreanos em seu território, e ainda a ligação existente por compartilharam do regime comunista, se tornaram, ao decorrer dos anos, premissas cada vez mais fracas e insustentáveis perante a comunidade internacional.

O pensamento convencional que admite a Coreia do Norte como sendo um Estado Tampão entre as tropas dos Estados Unidos na Coreia do Sul e a China, com quem partilha uma fronteira de mais de $1.400 \mathrm{~km}$, tem sido o mais recorrente quando o assunto é a política chinesa para a região. Essa perspectiva é tida como principal durante muito tempo devido a China, no início do século $X X$, ter sido 
invadida pelo Japão através da península coreana. Anos mais tarde, na década de 1950, com a Guerra da Coreia, a China viu-se ameaçada por uma outra invasão, desta vez por tropas estadunidenses (WANG, 2014).

Apesar de ainda haver desconfiança entre China e Estados Unidos ${ }^{8}$, segundo Wang (2014), o valor estratégico da Coreia do Norte como Estado Tampão, mesmo que ainda exista, diminuiu ao longo dos anos, principalmente após o restabelecimento das relações diplomáticas entre Beijing e Washington no final da década de 1970, bem como com o fim da União Soviética na década seguinte, e a aproximação oficial entre China e Coreia do Sul (WANG, 2014).

Não obstante, a postura provocativa que Pyongyang tem adotado desde seus primeiros testes com Armas de Destruição em Massa (ADM), contribui para o aumento das tensões na região, e em decorrência disso, para uma maior cooperação militar entre Estados Unidos, Japão e Coreia do Sul, fato que favorece a continuidade do pensamento convencional de Estado Tampão, uma vez que a China prossegue adotando uma postura ainda muito cautelosa e não tão incisiva em relação ao comportamento norte-coreano.

Outro pensamento convencional analisado por Wang (2014) é o de afinidade ideológica, onde a sobrevivência do regime comunista norte-coreano significaria para a China, não somente uma afinidade de sistemas, mas, principalmente a legitimação do regime político chinês, uma vez que com o colapso do sistema comunista fica cada vez mais difícil para a China sustentar esse tipo de regime político. Contudo, ao abrir seu mercado para o comércio internacional da maneira como fez a China ao buscar sua reforma e desenvolvimento econômico, acabou sendo vista como uma traidora da ideologia comunista pela Coreia do Norte. Portanto, cada vez mais o pensamento de afinidade ideológica entre Beijing e Pyongyang se mostra ultrapassado.

De acordo com David A. Welch (2016) em artigo à Foreign Affairs, a atitude do Primeiro Ministro Chinês, Xi Jinping, reforça a visão de que o comportamento

\footnotetext{
${ }^{8}$ Esse traço que ainda marca a relação China-Estados Unidos pode ser percebido com bastante clareza no discurso de GengShuang, porta-voz do Ministério das Relações Exteriores da China, em Conferência Regular de Imprensa, concedida em fevereiro de 2017. Ao ser perguntado sobre a movimentação militar dos Estados Unidos no mar do Sul da China, Shuang respondeu da seguinte forma: "China has not relevant reports. China always respects the freedom of navigation and overflight that countries enjoy in the South China Sea under international law. But we oppose relevant countries threatening and undermining the sovereignty and security of coastal states under the pretext of such freedom. We hope that relevant countries can do more for regional peace and stability".
} 
cauteloso chinês demonstra grande receio em outra área que caracteriza mais um pensamento convencional, a de fluxo de refugiados norte-coreanos para o território chinês.

Como explica Wang (2014), a China teme que um possível colapso da Coreia do Norte venha a implicar uma massa de refugiados norte-coreanos sem precedentes em seu território. A maior quantidade de migrantes norte-coreanos no território chinês foi registrada na década de 1990, período que marcou a história da RDPC com a Grande Fome. Desde então aproximadamente 200 ou 300 mil nortecoreanos deixaram seu país em função das dificuldades enfrentadas na Coreia do Norte, a maioria deles, porém, utilizam o território chinês apenas como meio mais viável de chegar à Coreia do Sul para só então, solicitar o refúgio.

Wang (2014), no entanto, diz que esse pensamento também se mostra insuficiente dada a ameaça que representa a Coreia do Norte atualmente. Em sua análise ela defende que mesmo com o colapso da RDPC gerando tamanho fluxo de refugiados, a China teria meios de conter e solucionar o problema, e prossegue explicando que para outros poderes como Estados Unidos, Rússia, Japão e Coreia do Sul, a desestabilização do nordeste asiático não é favorável, uma vez que China e Japão representam a segunda e quarta maiores economias mundiais, respectivamente. Uma crise humanitária então, afetaria a economia global. Por esses motivos, Wang (2014) defende que tanto os Estados Unidos, quanto os demais países estariam dispostos a cooperar com a China na resolução de um evento como esse, visão igualmente defendida por Welch (2016).

Por outro lado, o comércio entre os dois países tem se mantido mesmo após os testes nucleares da Coreia do Norte e das sanções adotadas pela China, essa última, porém, sendo a menos beneficiada nesse âmbito. Enquanto Beijing representa o maior parceiro comercial de Pyongyang, a China se beneficia muito mais do comércio com a vizinha, ainda vista como rival, Coreia do Sul, que já em 2010 somava $\$ 207$ bilhões, que com a cooperação econômica entre Coreia do Norte, que no mesmo ano era de $\$ 3.47$ bilhões (WANG, 2014). Segundo Shen (2013), o comércio entre China e Coreia do Norte era de $\$ 5.7$ bilhões em 2011 e $\$ 3.1$ bilhões em 2012. A RPC continuou a manter também ajuda nas áreas de energia e fertilizantes, bem como em outros setores.

A visão da manutenção de uma política ambivalente pode ser atenuada em 
função de uma China que, mesmo não sendo a parte mais beneficiada no âmbito econômico dessa relação, se demonstra relutante em cessar o comércio com a Coreia do Norte. Segundo Victor Cha (2017), mesmo aprovando a Resolução do Conselho de Segurança das Nações Unidas (RCSNU) 2321, que estipulava a redução do montante da importação de carvão da Coreia do Norte em dezembro de 2016, a China importou o dobro da quantidade determinada. Inicialmente, em função das sanções a China havia diminuído a quantidade de importação de carvão da RDPC, mas ainda assim continuou importando 9 . No entanto, a China ainda pode utilizar-se da exceção das Resoluções da ONU de "fins de subsistência".

Ainda segundo Cha (2017), a China teria concordado em importar 4000 toneladas métricas de gás liquefeito de petróleo (GLP) da Coreia do Norte pela primeira vez, o que pode funcionar tanto como fonte adicional de moeda estrangeira para a RDPC, quanto como um motivo adicional para que a China forneça petróleo bruto para processamento à Pyongyang.

De acordo com Eleanor Spencer (2017), em fevereiro de 2017 o Ministério do Comércio Chinês havia declarado a suspensão temporal das importações de carvão da Coreia do Norte. Em junho desse mesmo ano, a Corporação Nacional de Petróleo da China (CNPC), alegando incerteza no pagamento das transações por parte da Coreia do Norte, suspendeu as vendas de combustível à Pyongyang. Como um sinal de maior insatisfação com a RDPC, os principais bancos chineses começaram a dar sinais de que estavam trabalhando para paralisar as movimentações de contas norte-coreanas em suas agências.

De forma contraditória, no entanto, o comércio entre China e Coreia do Norte no primeiro semestre de 2017 já somava o montante de $\$ 2.6$ bilhões, o que representa $10 \%$ a mais que no mesmo período do ano anterior. Segundo Spencer (2017), a China ainda é a maior fornecedora de alimentos e energia da RDPC, responsável por $90 \%$ da soma total do comércio norte-coreano. Outros países como Estados Unidos, Japão e Coreia do Sul representavam $75 \%$ do abastecimento de comida da Coreia do Norte desde 1995, contudo, após a paralização indefinida das SPT em 2009, essa ajuda diminuiu substancialmente, e apenas a China continuou a

\footnotetext{
${ }^{9}$ O limite imposto pela RCSNU 2321 restringia o volume de importação de carvão norte-coreano pela China, para 7.5 milhões de toneladas métricas, ou $\$ 400.9$ milhões em 2017 . Em comparação, no ano anterior, a China havia importado 22.5 milhões de toneladas métricas de carvão da Coreia do Norte, ou o equivalente a $\$ 1.2$ bilhões, o que representa $14.5 \%$ a mais se comparado ao ano de 2015 .
} 
mantê-la de forma significativa.

Após o terceiro teste nuclear norte-coreano em 2009, conforme Kong (2017), e com a visita do ex-Primeiro Ministro Chinês, WenJiabao, à Coreia do Norte, o comércio entre os dois países intensificou-se, bem como a dependência da RDPC em relação a China. Já em 2013, depois da condução de novos testes nortecoreanos com ADM, e sob nova liderança chinesa, a RPC adotou sanções mais duras contra a Coreia do Norte. Não obstante, as empresas chinesas tanto privadas, quanto estatais, continuaram a manter suas transações econômicas com Pyongyang.

Em 2015, de acordo com Spencer (2017), China e Coreia do Norte cooperaram para a construção de rotas de transporte terrestre entre seus territórios, visando a facilitação, principalmente, da importação de carvão norte-coreano. Um outro projeto era a construção da Nova Ponte do Rio Yalu, conectando as cidades de Dandong e Sinujiu e que custaria $\$ 350$ milhões. A ponte cujo o prazo de entrega datava outubro de 2014, no entanto, ainda está inacabada, o que pode ser um indicativo de certo esfriamento na relação China-Coreia do Norte.

De acordo com Stanton, Lee e Klingner (2017), a maneira com que a China conduz sua política para com a Coreia do Norte deixa claro a dualidade em seu comportamento. Exemplo disso podem ser analisados em fatos como a venda de caminhões transportadores de mísseis por parte de companhias governamentais chinesas à RDPC; a permissão de transporte de ADM para os programas de mísseis balísticos e nuclear norte-coreanos, bem como o transporte de bens de luxo através dos portos chineses, e com destino à Coreia do Norte; e ainda a liberação de companhias e hackers norte-coreanos (os mesmos que seriam responsáveis pelo ataque à Sony Pictures em 2014) para atuar em território chinês. Além disso os bancos chineses, segundo descrito no artigo, continuam a fazer operações ilícitas em conjunto com o governo norte-coreano ${ }^{10}$.

Assim, apesar de reconhecer sua responsabilidade para com a comunidade internacional, a China continua cooperando com o regime de Pyongyang, uma vez que a estabilidade da península ainda representa um fator de interesse na sua

\footnotetext{
10 Um exemplo recente do descumprimento das sanções pela China e citado no artigo por Stanton, Lee e Klingner (2017) pode ser visto no episódio em que os Estados Unidos, em setembro de 2016, acusaram a Companhia de Desenvolvimento Industrial de Dandong Hongxiang de ajudar um banco norte-coreano, previamente sancionado, no processo de lavagem de dinheiro.
} 
BRUNA M. DIAS \& HELVÉCIO DE JESUS JR.

política para a região. Desta maneira, os benefícios econômicos da relação ChinaRDPC se mostram mais favoráveis à Coreia do Norte, enquanto Beijing se beneficia mais de aspectos concernentes aos seus interesses político-estratégicos.

\section{Análise de cenários para a relação entre China e Coreia do Norte}

Mais de uma década se passou desde o primeiro teste nuclear norte-coreano em outubro de 2006, e em 2017 com a mudança de governo dos Estados Unidos o aumento das tensões na península coreana se tornou quase inevitável. Com Kim Jong-Un no poder, desde 2011, a Coreia do Norte acelerou o desenvolvimento de seu programa nuclear. Só no ano de 2016 foram realizados 24 lançamentos com mísseis balísticos, além de dois testes nucleares, um em janeiro e outro em setembro. Até outubro de 2017 o total de lançamentos de mísseis norte-coreanos alcançou o número de 22, segundo dados da CNN. Em 4 de julho de 2017, dia em que os Estados Unidos comemoram sua independência, a Coreia do Norte realizou seu primeiro teste com míssil balístico intercontinental, que anunciou ser capaz de atingir qualquer lugar do mundo. Já em 29 de agosto e 15 de setembro foram conduzidos testes com mísseis sobre o território japonês, e em 3 de setembro deste mesmo ano, Pyongyang realizou seu sexto teste nuclear.

Em uma de suas respostas relacionadas ao assunto, o Ministro das Relações Exteriores Chinês Wang Yi disse que "[...] sanções e pressão são apenas metade da chave de resolução da questão nuclear. A outra metade é feita de diálogo e negociação". No entanto, ao mesmo tempo em que vemos a China insistir em adotar um viés mais diplomático para a resolução do conflito nuclear na região, também não podemos deixar de observar o fato de o governo chinês deixar transparecer sua insatisfação e crescente desconfiança com o aumento da presença militar estadunidense tanto no Mar do Sul da China, quanto na península coreana.

Segundo Wang (2014), o porta-voz do Ministério da Defesa Chinês já demonstrava, ainda na administração de Obama, a discordância da presença militar estadunidense no Pacífico chegando a dizer que qualquer aumento de cooperação militar na região demonstraria uma mentalidade da Guerra Fria, e que, portanto, não estaria contribuindo em nada para a construção da paz e manutenção da 
estabilidade na região. Ainda para Wang (2014), as provocações norte-coreanas servem como uma forma de justificativa a qual os Estados Unidos utilizam para manter sua presença militar na região, aumentando as tensões na península e, portanto, fazendo com que a desconfiança chinesa cresça de maneira a permitir que a Coreia do Norte continue a utilizar seu desenvolvimento nuclear como vantagem em ameaças.

Analisando a ocorrência dos fatos, e devido ao arrefecimento das tensões na península coreana nos anos de 2016 e 2017, tanto o aumento da presença militar estadunidense, quanto o incremento da frequência dos testes com ADM nortecoreanos, caracterizam fatores que podem levar a um provável cenário futuro e que passa a ser analisado a partir de agora.

Nesse cenário, teríamos uma das possibilidades mais recorrentes como resultados dessas provocações, que seria um primeiro ataque dos Estados Unidos à Coreia do Norte, como prometido por Trump, em função das ameaças nortecoreanas. Sob a perspectiva de um cenário como esse, o envolvimento de outros países como China e Japão, seria uma questão de tempo e necessidade. O Japão, dada a sua história na península e como indicado nos testes com mísseis balísticos de agosto e setembro, poderia muito bem ser atingido em uma ofensiva nortecoreana, o que, portanto, faria com que o Japão não tivesse outra escolha, a não ser entrar no conflito, ao lado dos Estados Unidos. Já a China, reviveria a sensação da Guerra da Coreia, desta vez, no entanto, em uma escala perigosamente maior, o que a deixaria, obrigada não apenas pelo Artigo II do Tratado de Amizade, Cooperação e Assistência Mútua, como em defesa de seu território e seus interesses na região, a entrar no conflito, apesar de análises como a de Shen (2006), dizerem que a China demonstra cada vez menos interesse em cumprir com o Tratado Sino-Norte-Coreano.

A possibilidade de que um conflito como esse deixe ambas as Coreias novamente devastadas não é nem de longe pequena, não para pelo menos uma delas, a do Norte. Com a RDPC completamente destruída, e consequentemente uma Coreia unificada, haveria maior tendência de alinhamento com os Estados Unidos e, portanto, a implantação de um regime democrático na região, como explica Wang (2014). 
A China que, segundo a análise dos pensamentos convencionais teme que com esse cenário haja um fluxo de refugiados norte-coreanos sem precedentes, veria seu território inundado por eles, especialmente nas cidades perto da fronteira com a então Coreia do Norte. Outro aspecto, seria o de que com uma vitória em um conflito como esse, os países do nordeste asiático aumentassem seu alinhamento com os Estados Unidos, o que representaria perda de poder para a China (SHEN, 2013).

Em um outro cenário, esse defendido por Stanton, Lee e Klingner (2017), podemos observar a alternativa de busca pela resolução do impasse entre Coreia do Norte e Estados Unidos com a adoção de uma postura mais assertiva na implementação das sanções e adoção das RCSNU, e não tão militar quanto no cenário anterior.

Nesse novo cenário, não só os Estados Unidos, mas também países como China, Coreia do Sul e Japão, teriam de adotar uma postura mais rígida para com a RDPC, cooperando uns com os outros na implementação integral de sanções de fato mais duras, o que levaria ao colapso do regime atuante em Pyongyang.

Para esses autores, o comportamento norte-coreano, e seu desenvolvimento nuclear sinalizam que já passou da hora de os Estados Unidos tomarem uma decisão final em relação a Pyongyang e pararem com a política dual de adotar sanções e ao mesmo tempo subsidiar a RDPC. Diversos acordos foram assinados entre Pyongyang e Washington durante as últimas três administrações dos Estados Unidos. No entanto, todos eles foram, um após o outro, quebrados pela RDPC ao continuar com seu desenvolvimento nuclear. A cada acordo Washington aliviava as sanções e proporcionava ajuda à Pyongyang, que posteriormente descumpria os tratados.

Por sua vez, Seoul, visando a abertura do mercado norte-coreano e a liberalização de sua economia, iniciou um programa de ajuda financeira e investimento na Coreia do Norte. A Coreia do Sul até mesmo tentou maior cooperação com a RDPC através da abertura de uma indústria intercoreana, 0 Complexo Industrial de Kaesong, que gerou emprego a mais de 54 mil nortecoreanos, e até 2016, \$100 milhões em divisas, sem informação de como foram utilizados pela Coreia do Norte. No entanto, a Coreia Sul com suspeitas de que o governo norte-coreano estaria utilizando o dinheiro obtido através do trabalho no 
Complexo em seu programa nuclear, deixou o projeto que mais tarde foi também sancionado pelas RCSNU aprovadas em 2016 em função dos testes nucleares norte-coreanos realizados naquele ano.

Assim, a Coreia do Norte, de acordo com Stanton, Lee e Klingner (2017), tem conseguido realizar operações financeiras ilícitas, e através da lavagem de dinheiro, financiar seu programa de desenvolvimento nuclear. Segundo relatórios das Nações Unidas e do Departamento de Justiça dos Estados Unidos, a maioria das transações norte-coreanas são feitas em dólares estadunidenses, o que dá ao Departamento do Tesouro dos Estados Unidos poder para cessar a fonte financeira da Coreia do Norte, uma vez que "quase todas as transações em dólares estadunidenses devem passar pelos bancos dos Estados Unidos" (STANTON; LEE; KLINGNER, 2017).

E de fato isso já aconteceu em 2005 quando Washington proibiu suas entidades tanto governamentais, quanto privadas de fazer qualquer operação com o Banco Delta Ásia em Macau, porém posteriormente, em 2007, o governo Bush na tentativa de resolver as disparidades com a Coreia do Norte, permitiu que suas transações voltassem ao normal. Depois do quinto teste nuclear norte-coreano, em 2016, o Departamento do Tesouro dos Estados Unidos "congelou os ativos de aproximadamente 200 entidades norte-coreanas" (STANTON; LEE; KLINGNER, 2017).

Stanton, Lee e Klingner (2017), defendem que essa medida tomada pelo Departamento do Tesouro dos Estados Unidos representa progresso na busca pela resolução do conflito na península. No entanto, é necessário que se faça mais do que isso. Na visão dos autores, o cenário que solucionará esse impasse, não está na volta das SPT, ou do diálogo diplomático como tão enfaticamente impele a China vez após outra, quando as tensões aumentam na península. Tampouco está na retirada ou encerramento das atividades militares estadunidenses na vizinha Coreia do Sul, uma vez que Pyongyang está resoluta em avançar com seu programa nuclear. Para eles, "a única esperança restante para a desnuclearização pacífica da Coreia do Norte está em convencê-la de que deve se desarmar e reformar, ou perecer".

Desta forma, através de coerção financeira, congelando totalmente os recursos de Pyongyang, e multando as entidades que continuarem a cooperar com o regime, os Estados Unidos em conjunto com as Nações Unidas e países como 
China, Coreia do Sul e Japão, trabalhariam na implementação completa das sanções, fazendo com que a fonte que sustenta o programa nuclear norte-coreano fosse interrompida, e apenas a ajuda necessária à população fosse permitida. A China então, segundo Shen (2013), deveria adotar sanções mais duras contra a RDPC ao mesmo tempo em que diminui sua ajuda e comércio com Pyongyang, trabalhando em conjunto com os Estados Unidos, Coreia do Sul e Japão para a desnuclearização da península.

Não obstante, existem análises que demonstram o lado negativo da adoção das sanções e como o resultado esperado pelo agente sancionador não é obtido em casos como o da Coreia do Norte por ser um país autocrático. Como explica Zanella (2011), ao impor as sanções é esperado que através da pressão feita pela população o governo mude sua forma de agir. $O$ resultado analisado na maioria dos casos de imposição de sanções, no entanto, é de que por serem governos autocráticos, pressupor que a população tem o poder de exercer qualquer tipo de influência sobre seus governos chega a ser quase impossível, o que gera o fracasso da maior parte das sanções a países com esse perfil.

O cenário que vê a cooperação e coerção como o meio mais plausível para a resolução do conflito na península coreana, pode até demandar mais tempo para apresentar resultados satisfatórios do que como com a solução do cenário anterior, que admite uma guerra na região, porém na visão de Stanton, Lee e Klingner(2017), ameaçar a sobrevivência do regime norte-coreano seria a melhor opção.

Não obstante, um terceiro possível cenário seria o de uma invasão chinesa à Coreia do Norte. Esse cenário assume que uma China ameaçada por uma invasão iminente dos Estados Unidos à Coreia do Norte, e analisando os riscos de ação para seus interesses, optaria por invadir a RDPC antes que as tropas estadunidenses pudessem iniciar qualquer operação.

No entanto, esse cenário, ainda que figure uma possibilidade, tem uma probabilidade muito menor de acontecer, dada a preocupação chinesa com a desestabilidade na península, uma vez que a China sempre enfatiza a estabilidade e desnuclearização da península coreana de forma pacífica e através de diálogo diplomático em seu posicionamento oficial. 
Todavia, segundo Welch (2016), o Presidente chinês, Xi Jinping, não tem tomado uma postura tão assertiva na busca pela resolução do problema nortecoreano, o que não é característico dele.

Wang Yi, atual Ministro das Relações Exteriores Chinês, após o último teste nuclear norte-coreano declarou em conferência com o Ministro das Relações Exteriores Francês, Jean-Marc Ayrault que "uma vez iniciada uma nova guerra na Coréia, os resultados não seriam nada além de perdas múltiplas. Ninguém poderá se tornar um vencedor". Além disso, em seus discursos, Wang tem sempre enfatizado a posição chinesa como aquela que busca a paz e a estabilidade na região, impelindo os outros países a resolverem o assunto através do diálogo diplomático.

\section{Conclusão}

Quando tratamos de analisar possíveis cenários que envolvem a questão nuclear norte-coreana, e principalmente quando esses são acompanhados do fator guerra, as possibilidades se tornam um tanto turbulentas. Em função da imprevisibilidade do comportamento da Coreia do Norte em relação ao seu programa nuclear, podemos esperar inúmeras combinações de cenários. Apesar dos três possíveis cenários analisados, é coeso mencionar que, como exposto no próprio artigo, a forma com a qual a Coreia do Norte trata a questão nuclear, caracteriza um comportamento de difícil de previsibilidade, e que por vezes pode se demonstrar belicoso, e por vezes pode adotar um caráter amistoso e diplomático. Tudo depende de seus interesses naquele momento, e de como a aplicação do seu poder de barganha vai ser utilizada.

Ao mesmo tempo, percebemos uma China que ao ver seus interesses político-estratégicos em jogo, prefere manter uma posição contraditória e que pode ser vista em discursos como o do Ministro das Relações Exteriores Chinês, Wang Yi, e falas de porta-vozes do governo chinês como, HuaChunying. Enquanto o Ministro Wang Yi, após o sexto teste nuclear norte-coreano, demonstrou um sinal de insatisfação com o comportamento da Coreia do Norte, em HuaChunying encontramos o apelo por diálogo e diplomacia. 
A China, que a partir de 2013 com o terceiro teste nuclear norte-coreano, passou a adotar sanções um pouco mais duras, mostra ao longo dos anos que apesar disso, não está disposta a esforços maiores e mais pragmáticos quanto a questão nuclear norte-coreana. Ao primar por uma península estável, e ao mesmo tempo temer as consequências de um possível conflito,a China, vez após vez, adota políticas contraditórias em sua relação com a Coreia do Norte. Como exemplo disso, o comércio entre China e Coreia do Norte atingiu seu nível mais alto em 2014, com $\$ 6.86$ bilhões. A China ainda mantém sua ajuda à Coreia do Norte através de importações de carvão e exportação de combustível, além de cooperar em outras áreas como alimentação.

Pensamentos convencionais analisados ao longo do artigo e utilizados para explicar a forma como a China se porta mesmo diante de uma ameaça nuclear na península coreana, de fato não conseguem mais sustentar a ambivalência de seu comportamento. A visão de que a China deve então tomar uma postura que demonstre rigidez em relação a Coreia do Norte, bem como maior responsabilidade com a comunidade internacional, como demanda seu papel hoje no cenário global, é defendida pela maioria dos analistas desta relação.

\section{Referências}

ALBERT, Eleanor. The China-North Korea relationship. Council on Foreign Relations. 2017. New York. Disponível em: <https://www.cfr.org/backgrounder/china-north-korea-relationship>. Acesso em: 29 set. 2017.

ASSOCIATED PRESS NEWS. China supports UN action on North Korea while urging talks. 7 set. 2017. Beijing. Disponível em: <https://apnews.com/8a1eb6632bd744cd8cf33e75eb85f3a9/China-supports-UNaction-on-North-Korea-while-urging-talks>. Acesso em: 12 out. 2017.

BERLINGER, Joshua. North Korea's missile tests: By the numbers.20 out. 2017.

Disponível em: <http://edition.cnn.com/2017/05/29/asia/north-korea-missiletests/index.html>. Acesso em: 22 out. 2017.

BOODEN, Christopher. Chinese foreign minister: No winners if Korea war breaks out. Associated Press News. 15 abr. 2017. Beijing. Disponível em: 
<https://apnews.com/498e3a3112da4708b08b8c7088093c3c/Chinese-foreign-

minister:-No-winners-if-Korea-war-breaks-out>. Acesso em: 12 out. 2017.

CHA, Victor. The meaning of China's coal ban on DPRK. Center for Strategic and International Studies. 20 fev. 2017. Washington, D.C. Disponível em: <https://www.csis.org/analysis/meaning-chinas-coal-ban-dprk>. Acesso em: 12 out. 2017.

CHINA. Ministry of foreign affairs. Foreign ministry spokesperson GengShuang's regular press conference on february 21, 2017. Beijing.Disponível em:<http://www.fmprc.gov.cn/mfa_eng/xwfw_665399/s2510_665401/2511_665403/t 1440264.shtml>. Acesso em: 12 out. 2017.

FENG, Zhu. Shifting tides: China and North Korea. China Security, n. 4, 2006, pp. 35-51. Disponível em: <https://www.issuelab.org/resources/435/435.pdf>. Acesso em: 5 maio 2017.

GLASER, Bonnie S. China's Policy in the Wake of the Second DPRK Nuclear Test. China Security, v. 5, n. 2, 2009, p. 33-45. Disponível em: $<$ https://asiafoundation.org/resources/pdfs/GlaserChinaSecurity2.pdf>. Acesso em: 14 abr. 2017.

KEOHANE, Robert O. The big influence of small allies. Foreign Policy, n. 2, 1971, p. 161-182. Disponível em: <http://www.jstor.org/stable/1147864?seq=1\#page_scan_tab_contents>. Acesso em: 14 dez 2017.

KHAN, Sulmaan. Unbalanced Alliances. Foreign Affairs. 18 fev. 2016. Disponível em: $\quad<$ https://www.foreignaffairs.com/articles/china/2016-02-18/unbalancedalliances>. Acesso em: 24 set. 2017.

KONG, Tat Yan. China's engagement-oriented strategy towards North Korea: achievements and limitations. The Pacific Review. 27 abr. 2017. Disponível em: $<$ https://www.researchgate.net/publication/316530623_China\%27s_engagementoriented_strategy_towards_North_Korea_achievements_and_limitations>. Acesso em: 5 set. 2017.

LEE, Hyeonseo. The girl with seven names. Great Britain: William Collins, 2015.

MELCHIONNA, Helena Hoppen. A questão nuclear da Coreia do Norte sob as perspectivas da China e dos EUA. 2011. 98 págs. Monografia (Trabalho de Conclusão de Curso de Relações Internacionais) - Universidade Federal do Rio Grande do Sul, Porto Alegre. Disponível em:

<http://www.lume.ufrgs.br/bitstream/handle/10183/40259/000827654.pdf?sequence= 1>. Acesso em: 7 abr. 2017.

MENEGAZZI, Silvia. China's foreign policy in northeast Asia: Implications for the Korean Peninsula. IstitutoAffarilnternazionali. 2017. Roma. Disponível em: <http://www.iai.it/sites/default/files/iaiwp1703.pdf>. Acesso em: 17 set. 2017. 
BRUNA M. DIAS \& HELVÉCIO DE JESUS JR.

RCSNU. Resolução do Conselho de Segurança das Nações Unidas 1874 (2009).Security Council Report. 12 jun. 2009. Disponível em: <http://www.securitycouncilreport.org/atf/cf/\%7B65BFCF9B-6D27-4E9C-8CD3CF6E4FF96FF9\%7D/NKorea\%20SRES\%201874.pdf>. Acesso em: 13 mar. 2017.

RCSNU. Resolução do Conselho de Segurança das Nações Unidas 2094 (2013).Security Council Report. 7 mar. 2013. Disponível em: <http://www.securitycouncilreport.org/atf/cf/\%7B65BFCF9B-6D27-4E9C-8CD3CF6E4FF96FF9\%7D/s_res_2094.pdf>. Acesso em: 13 mar. 2017.

RCSNU. Resolução do Conselho de Segurança das Nações 2321 (2016). Security Council Report. $\quad 30$ nov. 2016. Disponível em: <http://www.securitycouncilreport.org/atf/cf/\%7B65BFCF9B-6D27-4E9C-8CD3CF6E4FF96FF9\%7D/s_res_2321.pdf>. Acesso em: 13 mar. 2017.

SAVAGE, Timothy. Big brother is watching: China's Intentions in the DPRK. China Security, (local) v. 4, n. 4, p. 53-57, 2008. Disponível em: <http://nautilus.wpengine.netdna-cdn.com/wpcontent/uploads/2011/12/copy_of_08096Savage.pdf>. Acesso em: 13 set. 2017.

SHEN, Dingli. Lips and Teeth: It's time for China to get tough with North Korea. Foreign Policy. 13 fev. 2013. Shanghai. Disponível em: <http://foreignpolicy.com/2013/02/13/lips-and-teeth/>. Acesso em: 19 out. 2017.

SHEN, Dingli. North Korea's Strategic Significance to China.China Security, n. 4, 2006, p. 19-34. Disponível em: <https://www.issuelab.org/resources/434/434.pdf>. Acesso em: 14 abr. 2017.

SIVELS, Ciara. An assessment of North Korea's nuclear weapons capabilities. 2013. 34 págs. Trabalho Acadêmico (Trabalho de Conclusão de Curso - Ciência Nuclear e Engenharia) - Massachusetts Institute of Technologie, Cambridge, MA. Disponível em: <http://dspace.mit.edu/bitstream/handle/1721.1/82450/863051465MIT.pdf?sequence=2>. Acesso em: 2 jun. 2017.

SNYDER, Scott A. North Korea's testing decade. Council of Foreign Relations. 07 out. 2016. New York. Disponível em: <https://www.cfr.org/expert-brief/north-koreastesting-decade>. Acesso em: 15 jul. 2017.

STANTON, Joshua; LEE, Sung-Yoon; KLINGNER, Bruce. Getting tough on North Korea. Foreign Affairs. v. 96, n. 3, 2017. Disponível em: $<$ https://www.foreignaffairs.com/articles/north-korea/2017-04-17/getting-tough-northkorea>. Acesso: 21 set. 2017.

UNITED NATIONS.Security Council imposes fresh sanctions on Democratic People's Republic of Korea, unanimously adopting Resolution 2270 (2016). New York. 2016. 2 Disponível <http://www.un.org/press/en/2016/sc12267.doc.htm>. Acesso em: 13 mar. 2017.

VIZENTINI, Paulo Fagundes; PEREIRA, Analúcia Danilevicz.A discreta transição da Coreia do Norte: diplomacia de risco e modernização sem reforma. Rev. Bras. Polít. Int. $\quad$ v. $57, \quad$ n.2, p. 176-195, $2014 . \quad$ Disponível em: 
BRUNA M. DIAS \& HELVÉCIO DE JESUS JR.

<http://www.scielo.br/pdf/rbpi/v57n2/0034-7329-rbpi-57-02-00176.pdf>. Acesso em: 5 set. 2017.

WANG, Tianyi. Small State, Big Influence: China's North Korea Policy Dilemma. Georgetown Journal of Asian Affairs, p. 5-27, Fall-Winter 2014. Disponível em: $<$ https://repository.library.georgetown.edu/bitstream/handle/10822/712752/GJAA\%20 1.1\%20Wang.pdf;sequence=1>. Acesso em: 14 abr. 2017.

WELCH, David A. Paralyzed by Pyongyang. Foreign Affairs. 8 fev. 2016. Disponível em: $\quad<$ https://www.foreignaffairs.com/articles/china/2016-02-08/paralyzedpyongyang>. Acesso em: 21 set. 2017.

ZANELLA, Cristine Koehler. Pressões intransferíveis: uma análise do funcionamento interno das sanções econômicas. Conjuntura Austral. Vol. 2, n. 3-4, p. 79-91, 2011. Disponível em: <http://seer.ufrgs.br/ConjunturaAustral/article/view/18454>. Acesso em: 7 nov. 2017. 